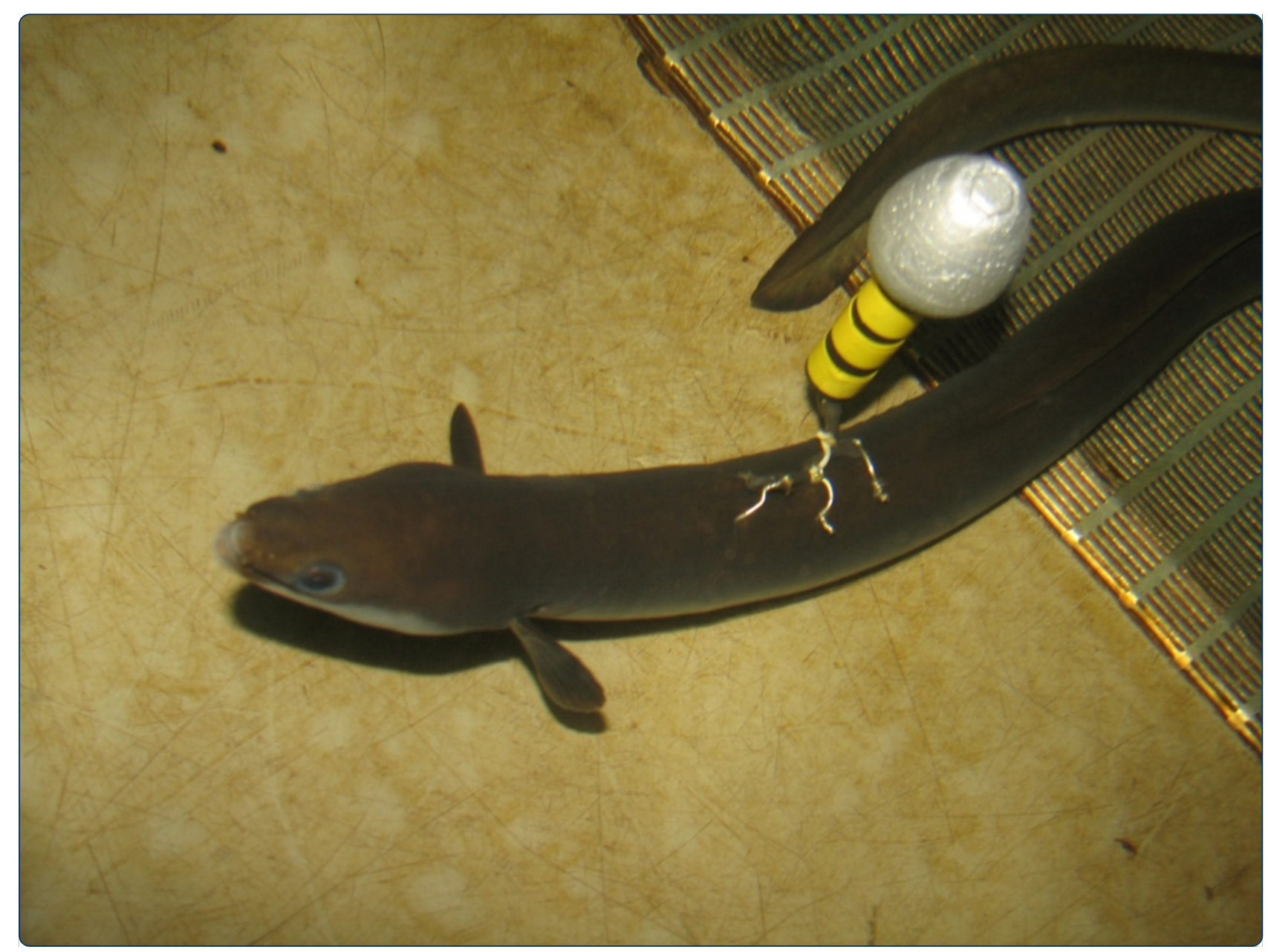

Development and testing of attachment methods for pop-up satellite archival transmitters in European eel

Økland et al.

C Biomed Central 


\title{
Development and testing of attachment methods for pop-up satellite archival transmitters in European eel
}

\author{
Finn Økland ${ }^{1 *}$, Eva B Thorstad ${ }^{1}$, Håkan Westerberg $^{2}$, Kim Aarestrup $^{3}$ and Julian D Metcalfe ${ }^{4}$
}

\begin{abstract}
Background: Four methods for attaching pop-up satellite transmitters to European eel were tested in the laboratory by recording long-term tag retention, growth and survival; short-term behavioral responses; and physical damage from attachments.

Results: All eels survived until they lost their tag, or until end of the six-month study. Specific growth rate did not differ between tagged fish and controls. Tag retention varied from $0 \%$ to $100 \%$ among attachment methods. A tagging method that uses the strength of the eel skin by attaching the tag to the skin at three points is recommended for ocean migration studies based on a long tag retention time, minimal behavioral reactions, negligible damage to the swimming muscle, and minimal physical damage both for fish retaining and losing the tag. Although tag retention was 50\% over six months, those losing their tags still retained them for 114 to 134 days. Another method had higher tag retention (100\%), but required the use of steel wires that moved upwards through the muscle over time. This method was regarded as less suitable because of a strong behavioral reaction in the first two days after tagging and damage to the swimming muscle. Results from 275 silver eels released on European coasts equipped with pop-up satellite transmitters or similarly sized pop-up data storage tags to study the ocean spawning migration indicated a large premature tag release. This was partly related to mechanical tag loss, but probably mainly to a high predation rate ( $>20 \%$ confirmed predations of eels with pop-up satellite transmitters). Mean time to premature tag release was 14 to 21 days (maximum nine months).

Conclusions: Laboratory and field data showed that pop-up satellite transmitters attached to eels can remain attached for six to nine months, but that tag retention is a challenge. Hiding behavior in a structured habitat increased the risk of entanglement and tag loss. In ocean migration studies, consideration should be given to transportation and release off shore instead of in shallower areas where they are more likely to seek the seabed and hide in structured habitats. Behavioral reactions indicate that data recorded during the first two to three days after tagging may not reflect natural behavior.
\end{abstract}

Keywords: Data storage tag, Satellite tag, External tagging, Tagging effect, Telemetry

\section{Background}

The development of pop-up satellite archival transmitters (PSATs) has made it possible to tag and follow ocean migration of the adult European eel Anguilla anguilla (L.) [1]. European eel are believed to undertake a spawning migration of 5,000 to $8,000 \mathrm{~km}$ to the Sargasso Sea, but little is known about this migration [2]. The PSAT collects

\footnotetext{
*Correspondence: finn.okland@nina.no

${ }^{1}$ Norwegian Institute for Nature Research (NINA), Trondheim NO-7485, Norway

Full list of author information is available at the end of the article
}

information on the environment of the fish such as light, pressure (depth) and water temperature. After a preprogrammed period it detaches from the fish, and a float on the tag brings it to the surface. From here, data is transmitted to polar-orbiting Advanced Research and Global Observation Satellites (ARGOS). The pop-up location is determined by the satellites and the archived environmental data is transmitted from the satellites to a relay station.

PSATs are relatively large and have to be attached externally. Negative effects of external tags may include reduced swimming speed and capacity due to the mass

\section{Biomed Central}


and increased drag imposed by the transmitter, fouling of the transmitter, entanglement in the environment, muscle damage and scale loss at the attachment site, transmitter loss, reduced growth and increased predation risk [3-7]. A large loss (91\%) of externally attached acoustic transmitters was recorded in a study of silver-phase American eel Anguilla rostrata [6], emphasizing that external tagging of eels is a challenging task. However, few studies exist on the effects of external tagging in eels.

In a study covering the first $1,300 \mathrm{~km}$ of the ocean migration of European eel with PSATs, the horizontal net migration speed varied from 5 to $25 \mathrm{~km} \mathrm{day}^{-1}$ (mean $13.8 \mathrm{~km} \mathrm{day}^{-1}$ ), which was lower than would be required (mean $35 \mathrm{~km} \mathrm{day}^{-1}$ ) to reach the Sargasso Sea in the following spawning season [1]. It might be that eels increase travel efficiency in the last part of the ocean migration not covered by that study, but swim speeds may also have been reduced due to negative effects of the PSATs. Two forces act on an animal tagged with a PSAT, these are lift due to the tag's buoyancy and drag as the tag is moved through the water. A more than twofold increase in swimming cost caused by PSATs has been recorded [8]. The oxygen consumption was increased and the swimming performance was reduced, and the results suggested that the drag rather than the lift created by the tag may have been the more crucial factor impairing swimming performance. In another study, it was found that the tag increased oxygen consumption during swimming, and minimum cost of transport was elevated by $26 \%$ [9]. Optimal swimming speed remained unchanged, whereas critical swimming speed decreased significantly.

It follows that one reason for not yet being able to follow European eel all the way to the Sargasso Sea may be the increased buoyancy and drag, reduced swimming capacity and increased energy costs caused by the tag. Another factor that can shorten the distance over which the migration can be followed is the transmitter detaching prematurely from the fish. Attaching PSATs to eels is difficult for several reasons. Firstly, the cross-section of the eel around the area where the attachment has to be done is almost circular, and attachments through the dorsal muscle may gradually move up towards the back of the eel. Secondly, eels have no scales to hold an external attachment in place. Thirdly, the animal is extremely flexible and may try to bite or push off the attachment with the tail or mouth. Finally, eels can enter narrow crevices between rocks and other structures in the environment after release and this may cause the tag to be dislodged.

For both animal welfare and data quality, it is important that the external attachment influences fish behavior as little as possible and the tag remains in place for as long as possible. The main objective of this study was to develop and test external attachment methods for
PSATs on European silver eels. This was done in the laboratory by:

1. comparing long-term tag retention and eel survival across four different external attachment methods

2. monitoring short-term behavioral response to being tagged, and

3. assessing physical damage to the fish in relation to the different attachment methods.

In addition, tag retention was evaluated in 275 silver eels that were tagged with PSATs or similarly sized pop-up data storage tags (PDSTs) and released in field studies on European coasts.

\section{Results}

\section{Laboratory study}

Survival and tag loss

All eels survived until they lost their tag, when they were removed from the holding tank and killed, or until the end of the study for those not losing their tags. All control fish survived the six-month study. In total, 13 eels (54\%) lost their tags before the end of the study period; no eels (0\%) tagged with the Økland method lost tags, four eels (67\%) tagged with the Jellyman and Tsukamoto method lost tags, three eels (50\%) tagged with the Westerberg method lost tags, and all eels (100\%) tagged with the Økland-Westerberg anchor implant method lost tags (Table 1). Those tagged with the Jellyman and Tsukamoto method lost their tags 4 to 90 days after tagging (average 42 days, two fish had already lost their tags in the structured habitat four days after tagging), those tagged with the Westerberg method lost their tags 114 to 134 days after tagging (average 127 days), and those tagged with the Økland-Westerberg anchor implant method lost their tags 4 to 21 days after tagging (average 14 days, two fish had already lost their tags in the structured habitat four days after tagging).

\section{Growth rate}

During the first four weeks, the loss of body mass for fish still retaining tags averaged $24 \mathrm{~g}$ (range 45 to $0 \mathrm{~g}$, SD $23 \mathrm{~g}$ ). Mean specific growth rate was $-0.0011 \mathrm{~g}^{-1 a y}{ }^{-1}$ (range -0.0042 to 0 , SD 0.0013), which did not differ from the control fish (Mann-Whitney $U$ test, $U=63.0, P=0.52$ ).

\section{Behavioral reactions after tagging}

Half or more of the individuals in each group showed behavioral reactions to being tagged, especially during the first three hours after tagging (Figures 1 and 2). The average number of abnormal behaviors during the 10-min observation was especially high in eels tagged with the Økland method. The number of abnormal behaviors 
Table 1 Overview of tag loss (number of eels, $n$ ) for the different attachment methods during the laboratory experiment

\begin{tabular}{lccccc}
\hline Attachment method & $\begin{array}{c}\text { Total number of eels } \\
\text { tagged }(\mathbf{n})\end{array}$ & $\begin{array}{c}\text { Tag loss } \mathbf{0} \text { to } \mathbf{2} \\
\text { days }(\mathbf{n})\end{array}$ & $\begin{array}{c}\text { Tag loss } \mathbf{2} \text { days to } \mathbf{4} \\
\text { weeks (n) }\end{array}$ & $\begin{array}{c}\text { Tag loss } \mathbf{4} \text { weeks to } \mathbf{6} \\
\text { months (n) }\end{array}$ & $\begin{array}{c}\text { Tag loss entire study } \\
\text { period (n) }\end{array}$ \\
\hline Økland & 6 & 0 & 0 & 0 & 0 \\
Jellyman and Tsukamoto & 6 & 2 & 2 & 0 & 4 \\
Westerberg & 6 & 0 & 3 & 0 & 3 \\
Økland-Westerberg & 6 & 3 & 3 & 0 & 6 \\
\hline
\end{tabular}

The experiment is divided into three time periods; zero to two days after tagging when the fish were kept in the structured habitat, two days to four weeks after tagging; and four weeks to six months after tagging.

decreased during the first 36 hours after tagging. In three of the tagged groups, no abnormal behaviors were seen by $57 \mathrm{~h}$ after tagging, whereas abnormal behaviors still occurred in fish tagged with the Økland-Westerberg anchor implant method. None of these abnormal behaviors were seen in the control fish, nor were they observed during occasional observations of the fish later in the study.

A special feature of eels is that they can swim backwards. Eels were observed swimming backwards and rolling around on their own body axis in all groups of tagged fish.
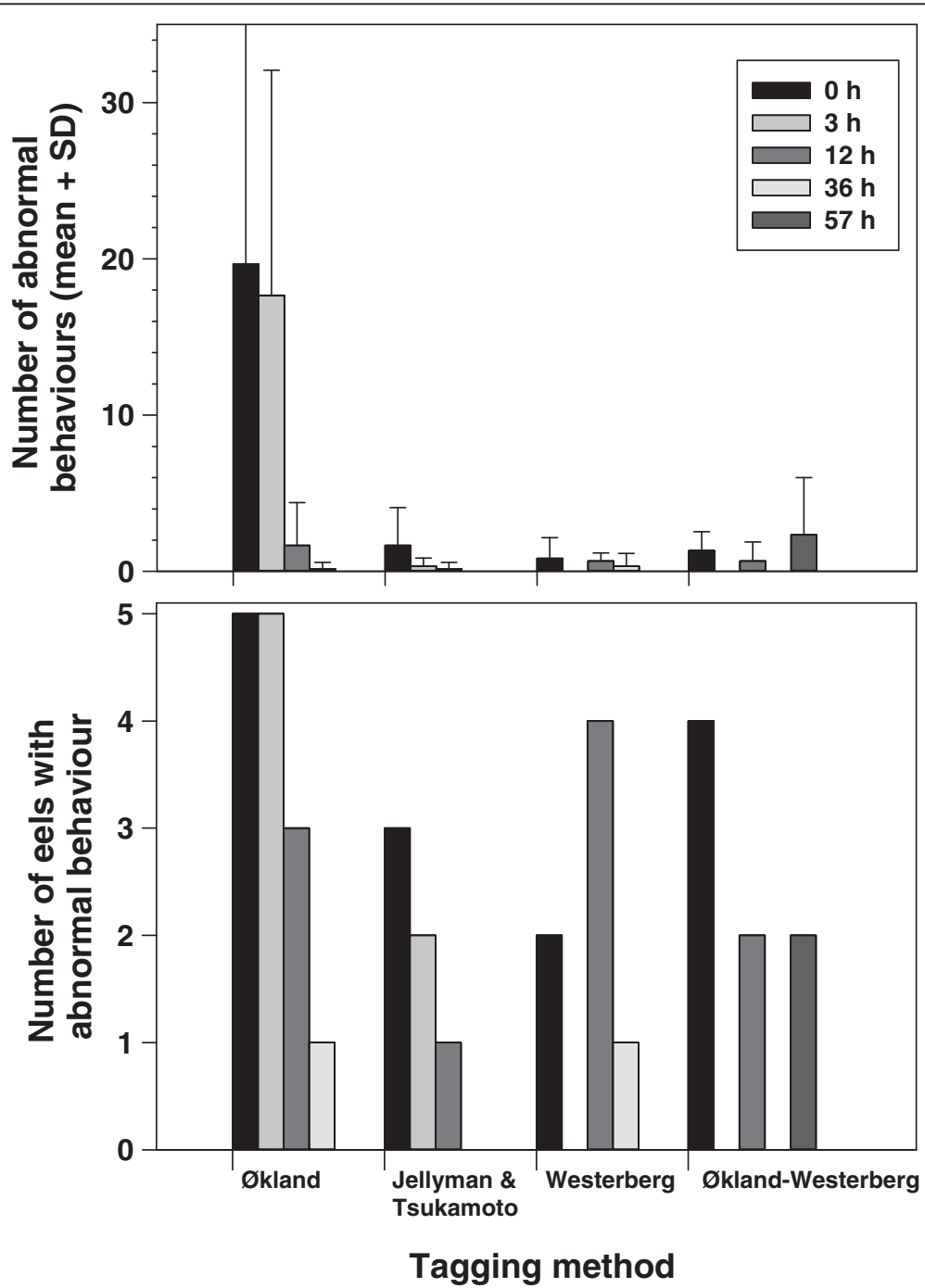

Figure 1 Mean number of abnormal behaviors observed per fish (upper panel) and number of eels showing abnormal behavior (lower panel) during a 10-min observation period $0 \mathrm{~h}, 3 \mathrm{~h}, 12 \mathrm{~h}, 36 \mathrm{~h}$ and $57 \mathrm{~h}$ after tagging. The fish were tagged with four different methods; the Økland method, Jellyman and Tsukamoto method, Westerberg method and Økland-Westerberg anchor implant method ( $n=6$ fish in each group). Abnormal behavior covers the sum of observed roll, backward swimming, tail, bite and 'panic' behaviors. 


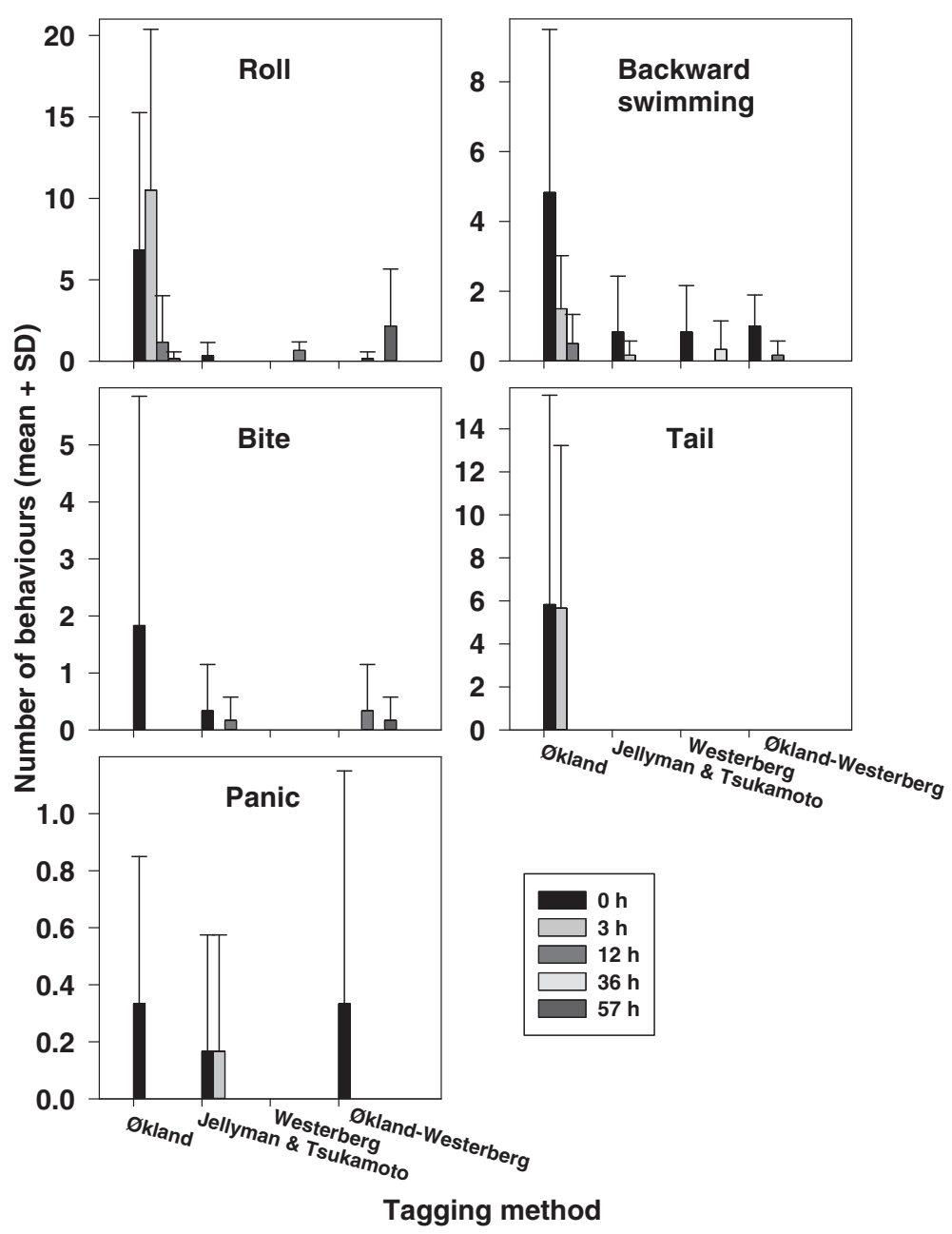

Figure 2 Mean number of abnormal behaviors (roll, backward swimming, biting tag area, exploring tag area with the tail and 'panic') observed per fish during a 10-min observation period $0 \mathrm{~h}, 3 \mathrm{~h}, 12 \mathrm{~h}, 36 \mathrm{~h}$ and $57 \mathrm{~h}$ after tagging. The fish were tagged with four different methods; the Økland method, Jellyman and Tsukamoto method, Westerberg method and Økland-Westerberg anchor implant method ( $n=6$ fish in each group).

Eels were observed trying to bite the tag in fish tagged with all methods except the Westerberg method. Only fish tagged with the Økland method were observed to use the tail to explore the area where the tag was attached. Some eels had a very strong behavioral reaction with sudden burst swimming incidents, and this 'panic' reaction was recorded for individuals in all groups, except for those tagged with the Westerberg method.

\section{Physical damage to the fish caused by tagging}

Økland method: The two plastic plates attached to each side of the fish moved between 1 and $2 \mathrm{~cm}$ up through the back of the eels, and the steel wire between them became u-shaped in the muscle. This happened in all eels, independent on size, but the largest movement of the plastic plates was in the largest eels. Despite this, the eels appeared to be in good condition and the skin had healed where the plates were originally attached. Some eels had skin erosion in an area surrounding the silicone pad. For the eels tagged with a plastic plate on one side and plastic plate with silicone pad on the other side, three eels had larger eroded areas on the side without the silicone pad after six months, whereas for the two other eels no difference was seen.

Jellyman and Tsukamoto method: Several of the tag losses were caused by the wire lock at the end of the Teflon-covered wire slipping off. With a better quality lock, this could have been avoided and the result would probably have been much better. Aside from the tag loss, the main problem with this method was keeping the plates aligned flat on the side of the eels. Often the plates were dragged upwards and dug wounds into the muscle.

Westerberg method: Of the three eels that still had their tags attached at the end of the six-month study 
period, one tag was still fastened in all three attachment points, one tag in the second and third attachment point, and one tag in only the third attachment point. This demonstrated that the rig worked as anticipated; by placing the drag first on the front wire, then having the attachment points further back as a security if the first one loosened. Where the attachment points had come loose, the skin had healed completely. At the attachment points still holding the tag there was a 2 to $4 \mathrm{~mm}$ channel just under the skin around the wire, but even where the drag had lifted the skin it appeared to be healthy with normal coloration.

Økland-Westerberg anchor implant method: The major problem with this method was that the attachment wire from the tag came loose from the anchor wire implanted in the fish. The wire from the tag rested in only a small bare area between the rubber tubes on the anchor wire implanted in the fish. This resulted in movements of the tag and the anchor wire implanted under the skin moved sideways until the tag came loose.

\section{Tag retention of silver eels released in field studies on European coasts}

The data returned from the PSATs varied between individuals (Table 2). Some tags never achieved uplinks to the ARGOS system and some had a data return less than 5\% - making analysis of behavior impossible. For the remaining tags, data showed varying periods of eel behavior before the tag was swallowed by a predator, sank to the seabed, or rose to the surface. The majority of the tags were released before the pre-programmed date by the constant pressure release, which was activated after four days of constant pressure. The constant pressure release was disabled for the first 30 days after deployment. Hence, if a tag surfaced during this period, it must have become detached from the fish for other reasons than being under constant pressure. Predation was confirmed in 34 cases when the daylight signal was blocked out for several days with simultaneous diving activity near the surface. The tag was released at the pre-programmed date in only one case among those attached with the Økland method (126 days) and in seven cases among those attached with the Westerberg method (six after 157 days and one after 98 days). Of the 22 PDSTs recovered, six were released at the pre-programmed date (two after 140 days and four after 60 days). All returns of long-distance trajectories of PDSTs are from the beach finds to where they were carried by wind and currents. A few shorter returns are from entanglements in fishing gear. Six PDST tags malfunctioned and there was insufficient data for analysis. Mean time from fish release to premature loss of the PSATs was 14 days for eels tagged with the Økland method and 18 days for eels tagged with the Westerberg method (Table 3). The corresponding number for the PDST tags was 21 days. However, it should be noted that more than $10 \%$ of the PSATs attached with the Westerberg method remained attached to the eel for more than 140 days.

\section{Discussion}

\section{Laboratory study}

The results in this study confirmed that a major challenge when attaching PSATs to European eel is to achieve a suitable tagging method that reduces tag loss and minimizes the physical damage to the fish. On a positive note, the results also demonstrated that it is possible to tag eels with external tags that are retained for six months. However, tag retention may be lower in ocean migration field studies than in laboratory studies, because the drag may be larger in migrating eels than in fish kept in tanks.

Eels are known to bury and hide in mud, gravel, vegetation and among stones and other structures both when waiting for prey to come near during feeding, or during periods of inactivity $[2,10]$. Results from keeping eels in a structured habitat in this study indicated that such hiding behavior increased the chance of losing external tags. A similar conclusion was reached in a tagging-effect study of the eel-like fish Gadopsis bispinosus [7], which inhabits interstitial spaces among cobbles and boulders. However, in this study, most tag losses occurred with fish tagged using the Jellyman and Tsukamoto and the Økland-Westerberg anchor methods, which did not have optimal mechanical implementation. Both methods can be improved by using better fit devices. The main conclusion is that external attachment seems robust and can withstand much mechanical abuse during the first few weeks after tagging, but that later losses occur due to rejection of the attachment. In ocean migration studies, tagged eels may be transported and released off

Table 2 Overview of data return from silver eels tagged with pop-up satellite archival transmitters and released on European coasts during the Galathea and EELIAD projects

\begin{tabular}{llllll}
\hline $\begin{array}{l}\text { Attachment } \\
\text { method }\end{array}$ & $\begin{array}{l}\text { Total number } \\
\text { tagged }(\mathbf{n})\end{array}$ & $\begin{array}{l}\text { Never achieved uplinks } \\
\text { to the ARGOS system }(\mathbf{n})\end{array}$ & $\begin{array}{l}\text { Too little data retrieved } \\
\text { for meaningful analysis }(\mathbf{n})\end{array}$ & $\begin{array}{l}\text { Premature pop-up } \\
\text { with data retrieved }(\mathbf{n})\end{array}$ & $\begin{array}{l}\text { Regular pop-up at } \\
\text { pre-programmed date }(\mathbf{n})\end{array}$ \\
\hline Økland & 97 & 24 & 10 & 62 & 1 \\
Westerberg & 63 & 10 & 7 & 39 & 7 \\
\hline
\end{tabular}

Data are given as number of eels ( $n$ ) in each category. ARGOS: Advanced Research and Global Observation Satellites. 
Table 3 Time from release on European coasts until premature pop-up of pop-up satellite archival transmitters and pop-up data storage tags for silver eels tagged during the Galathea and EELIAD projects

\begin{tabular}{lcccccc}
\hline $\begin{array}{l}\text { Attachment method } \\
\text { and tag type }\end{array}$ & Number of eels $(\mathbf{n})$ & Mean time (days) & SD & Minimum time (days) & Median time (days) & Maximum time (days) \\
\hline Økland PSAT & 62 & 14.1 & 35.7 & 0.5 & 8.0 & 273.0 \\
Westerberg PSAT & 39 & 18.1 & 28.5 & 0.7 & 7.3 & 147.6 \\
Westerberg PDST & 10 & 21.0 & 28.5 & 1.6 & 6.4 & 85.6 \\
\hline
\end{tabular}

PDST: pop-up data storage tag; PSAT: pop-up satellite archival transmitters; SD: standard deviation.

shore instead of in shallow areas, or near shore, where it is more likely that they will seek the seabed and hide and move in structured habitats. Alternatively, it could be argued that a recovery period on the seabed before starting migration may be beneficial and decrease the predation risk.

In terms of tag retention, the Økland method showed the best result, with no tags lost during the six-month study period. A similar result was obtained in another laboratory study when the same tagging method was used, with $100 \%$ tag retention in 15 eels over a fivemonth period ( $\mathrm{F} \varnothing$ and HW, unpublished results). However, eels tagged with the Økland method showed the strongest behavioral reaction to being tagged. Eels tagged with this method also had wires attached through the swimming muscle that moved up through the muscle over time. European eels tagged with the Økland method in a field study showed a slower progression than would be expected if they were to reach the Sargasso Sea in time for the spawning period [1]. It is not known whether this was partly related to the fact that they had wires attached through the swimming muscle. As long as the effect of introducing wires through the swimming muscle is not known, we recommend using the Westerberg method instead of the Økland method, although tag retention was poorer. However, it should be noted that with the Westerberg method, eels that eventually lost their tags still retained their tags as long as 114 to 134 days. From a fish welfare perspective, the Westerberg method seemed more favorable. Eels tagged with this method showed the least behavioral reaction to being tagged. Further, the tag was attached only in the skin, and did not interfere with the swimming muscle to the same extent as the Økland method. Where the tag attachments were lost, the skin healed completely. Hence, both for fish retaining and those losing the tag, the injuries at the attachment sites were small when using the Westerberg method. Where the Økland method is still used, we recommend using silicone pads with rounded shapes under the plastic plate at the side of the fish to minimize skin erosion. If plastic plates are used on their own, it is important that they are rounded and have no sharp structures that may increase skin erosion.
The Jellyman and Tsukamoto method may potentially be better than suggested by the results in this study, as it seemed the wire locks used were not of good quality. However, field studies using this method in longfin eel (Anguilla dieffenbachia) have also shown premature loss of transmitters, with tags being retained from only a few days up to 60 to 90 days for most fish, with a maximum attachment period of 161 days [11-13]. The main problem with this method was keeping the plates aligned flat on the side of the eels without being dragged upwards and digging into the muscle. The advantage with this method is that the wire can run under the skin and not through the swimming muscle. We recommend further refining, testing and development of the method before using it in large-scale field studies.

The Økland-Westerberg anchor implant method was the least invasive of the methods tested, but also the one with the lowest tag retention. The weakness of the method was the loose attachment point between the wire from the tag and the anchor in the fish, which caused sideways movements of the anchor until the wire from the tag slipped off the anchor bar. It should be possible to improve this design, but until that is done and tested, we would not recommend using the method for long-term field studies or in structured environments.

During the experiment, body mass of the individuals was only slightly reduced, and specific growth rate did not differ between tagged and control fish. However, if lipid were replaced by water, loss of body lipid may not be reflected as reduced body mass. Hence, it cannot be fully excluded that carrying a tag increased energy expenditure in the experimental fish. Measurement of body lipid content in live fish may be included in future tagging-effect studies.

The behavioral reactions observed during the first few days after tagging may indicate that data recorded during the first days in field studies of European eel may not reflect natural behavior, and that data from this period should be excluded from analyses. We recommend that field data be examined carefully in the first days of tracking and compared with later behavior to identify whether there are any appreciable differences. The behavior recorded with eels rolling around their own body axis, 'panic' reactions, backward swimming, 
and exploring the tag with the tail or biting it were believed to be an effect of tagging, as these behaviors were never seen in the control group or other untagged fish. Further, these behaviors disappeared progressively during the days following tagging. We are not aware of tagging-effect studies in other fish species that have reported such strong behavioral reactions to tagging as seen in these externally tagged European eel. On the contrary, European eels tagged with surgically implanted transponder tags showed a reduced activity level after tagging compared with control fish [14]. There are also field studies of other fish species that have reported a behavioral effect of handling and tagging by either decreased or increased activity levels during the few days after tagging [15-17]. Further, European eel biting at tag surgery sites has previously been observed [18].

The spectacular and frequent vertical migrations observed during the ocean migration of both European eel and longfin eel that cover several hundred meters depth $[1,13]$ are not likely to be tagging effects on behavior, but are most likely their natural migration behavior. This is because the vertical migration behavior was consistent over extended periods of time during the ocean migration and not the type of short-term phenomenon as the behavioral reactions to tagging observed in the present study. Further, the systematic diel movements recorded during the ocean migration is not expected to be a result of a tagging effect. Finally, a similar vertical behavior was recorded for European eel tagged with much smaller and surgically implanted transmitters in the body cavity [19].

\section{Tag retention of silver eels released in field studies on European coasts}

During the EELIAD [20] and Galathea [21] projects, both the Økland and Westerberg methods were used on silver eels released on European coasts equipped with PSATs or PDSTs to study the ocean migration towards the spawning grounds. These studies demonstrated that it is possible to tag eels with PSATs that remain attached to the fish for nearly nine months during the ocean migration. However, data extending up to the pre-programmed pop-up date was only collected from $5 \%$ of the eels, and there were many premature tag releases. Time from fish release until premature pop-up of PSATs was only 14 and 18 days for the two tagging methods, respectively, and there were no clear differences between the attachment methods in tag retention times. The shorter time from tagging until premature pop-up in the field compared to the laboratory study indicates that causes other than rejection or mechanical failure were probably responsible. The light sensor and behavior data from the PSATs showed that more than $20 \%$ were blacked out for several days and that most likely they were swallowed by a predator. The proportion of tags with premature release was higher with the Økland tagging method, which may indicate that the predation risk was higher for this group. However, it is not possible to interpret whether this was related to the different tagging methods, or to different release sites and years. Eels tagged with the Økland method were released on the east coast of Ireland and in the Bay of Biscay. Most of the cases with a long tag retention time using the Westerberg tagging method were from releases on the Swedish west coast, where the predation pressure may have been lower.

\section{Conclusions}

Laboratory studies showed that eels can be tagged with PSATs that remain attached to the fish for six months, and field data showed that tags can remain attached for up to nine months, but long-term tag retention remains a challenge. A tagging method that uses the strength of the eel skin by attaching the tag to the skin in three attachment points is recommended for ocean migration studies based on a long tag retention time, minimal behavioral reactions, lack of damage to the swimming muscle, and minimal physical damage both for fish retaining and losing the tag. Hiding behavior in a structured habitat increased the risk of entanglement and tag loss. In ocean migration studies, tagged eels should therefore be transported and released off shore instead of in shallower areas where they more likely seek the seabed and hide in structured habitats. Behavioral reactions indicate that data recorded during the first two or three days after tagging may not reflect natural behavior.

Developing and evaluating new attachment methods for PSAT tagging is costly, time consuming and often a neglected priority in migration projects. However, the results and quality of the data recorded depend on the fish handling and tagging procedures and our understanding of how the tag influences the behavior of the eel. The attachment method recommended here is a compromise between increasing tag retention, reducing behavioral reactions following tagging, and reducing damage to the swimming muscle. There is still room for significant improvements and, until new and smaller tags are available, tagging methods should continue to be improved and evaluated to better understand how this tag influences the behavior of the animals. Field studies of silver eels tagged with PSATs have shown regular diel vertical migration in individuals without any erratic movements that could indicate potential tagging effects. However, we do not know to what extend the speed, direction and energy expenditure during the silver eel ocean migration is compromised by attaching PSATs.

\section{Methods}

\section{Experimental protocol of the laboratory study}

Eels $(\mathrm{n}=32)$ were captured in a Wolf trap $150 \mathrm{~m}$ upstream from the sea in the River Imsa in southern Norway, during 
downstream migration in September and October 2009. All were female silver eels at migration stage IV or $\mathrm{V}$ $[22,23]$. They were held in a dark 5,000 l holding tank in salinity $8 \%$ for up to four weeks until tagging on 11 or 12 October 2009 (water temperature $9^{\circ} \mathrm{C}$ ). The eels were randomly allocated to one of five groups. Four groups ( $\mathrm{n}=6$ eels in each group) were tagged with dummy PSATs using different attachment methods (see below), and the remaining fish $(\mathrm{n}=8)$ constituted a control group. The dummy tags were modeled on the X-tag (Microwave Telemetry, Inc., Columbia MD, USA). Before tagging, eels were anesthetized in an aqueous solution of metomidate $\left(40 \mathrm{mg} \mathrm{l}^{-1}\right)$ [24]. There was no difference in body size between the groups (average body length $74 \mathrm{~cm}$, range 60 to $94 \mathrm{~cm}, \mathrm{SD}=71$, Kruskal Wallis test $X^{2}=6.0, P=0.11$; average weight $782 \mathrm{~g}$, range 558 to $1,940 \mathrm{~g}, \mathrm{SD}=295$, Kruskal Wallis test $\left.\chi^{2}=2.6, P=0.46\right)$. Individuals were identified using tape patterns with different colors attached to the dummy tags. The control fish had a passive integrated transponder (PIT-tag) injected into the body cavity using a hypodermic needle for individual identification. The mass of the dummy PSATs was $45 \mathrm{~g}$ in air, and they were positively buoyant in water $(0.5 \mathrm{~g})$. Total length of the dummy PSAT was $122 \mathrm{~mm}$ (stem $75 \mathrm{~mm}$, head $47 \mathrm{~mm}$ ), and the diameter of the stem was $16 \mathrm{~mm}$ and of the head $35 \mathrm{~mm}$.

After tagging, the eels were kept for three days in a dark $400 \mathrm{l}$ tank. During this period, five observations of the eels' behavior were made visually and by video recording by opening the lid for a 10 -min period $0 \mathrm{~h}, 3 \mathrm{~h}$, $12 \mathrm{~h}, 36 \mathrm{~h}$ and $57 \mathrm{~h}$ after tagging. Five types of abnormal behavior that were believed to be an effect of tagging were identified:

1. Roll. The eel rolled around its body axis, occasionally ending up on the bottom with its ventral side up.

2. Backward swimming. The eel suddenly swam backwards, for no apparent reason.

3. Tail. The eel explored the area were the tag was attached with the tip of its tail.

4. Bite. The eel turned its head and tried to bite the tag.

5. Panic. The eel performed sudden burst swimming incidents for no apparent reason, best described as a panic reaction.

After three days, the eels were moved to a large pool (salinity $8 \%$ ) with rocks, roots and concrete tubes where the likelihood of snagging and rubbing off tags was considerably increased compared with the situation in a normal hatchery tank. The eels were kept in the structured habitat for two days, a period sufficient for studying the behavior of the eels and possible immediate tag loss under such conditions. Subsequently, they were transferred to a dark 7,000 l circular tank for the remainder of the study period (mean water temperature $9^{\circ} \mathrm{C}$, range 4 to $12^{\circ} \mathrm{C}$, SD 1.7). The salinity was increased from 8 to $36 \%$ (full seawater salinity) during the first three days and was kept at approximately 36 during the rest of the study. The eels were inspected four weeks after tagging (on 10 November 2009), and the project was terminated six months after tagging (16 April 2010). Eels were checked daily and those that prematurely lost their tags were taken out of the tank and killed. The eels were not fed as they do not normally feed once they have embarked upon their migration in seawater. All photos shown were taken one to three days after tagging.

Specific growth rate for individuals during the first four weeks was calculated as follows [25]:

$$
\mathbf{g}=\left(\ln W_{4 \text { week }} \ln W_{0}\right) / T
$$

where $\mathrm{W}_{4 \text { week }}$ is the wet mass after four weeks, $\mathrm{W}_{0}$ the wet mass at tagging and $\mathrm{T}$ the duration in days.

\section{Description of tagging methods}

The four different tagging methods tested are described in the following.

\section{$\varnothing$ kland method}

The method involved attaching two rigid plastic plates $(10 \times 45 \times 2 \mathrm{~mm})$ to the back of the eel, one on each side, held in place with a stainless steel wire though the dorsal musculature of the animal (Figure 3). The tag was attached by a braided nylon cord running from the tag down to the plastic plates. The distance from the tag to the back of the fish was 2.0 to $2.5 \mathrm{~cm}$, to reduce the mechanical contact with the skin. To prevent the plastic plates from cutting into the skin, the sides were rounded and 4-mm-thick silicone pads were placed between the plastic plates and the skin. The plastic plates were attached by inserting two hollow needles through the dorsal muscle of the eel just above the back bone (that is, approximately $1.5 \mathrm{~cm}$ below the top of the back in a $2 \mathrm{~kg}$ eel), parallel and $33 \mathrm{~mm}$ apart. A $0.8 \mathrm{~mm}$ steel wire was run through the holes in the plastic plates and through the swimming muscle of the fish, guided by the hollow needles. The needles were then removed and the wire was pulled taut to hold the plastic plates in position at the side of the fish and closed by twisting the two ends of the wire around each other. Excess wire was cut off. Five of the six eels tagged with this method were tagged with only the plastic plate on one side and with the plastic plate and silicone pad on the other side, for a comparison. This method is slightly modified from that used by Aarestrup et al. [1]. 

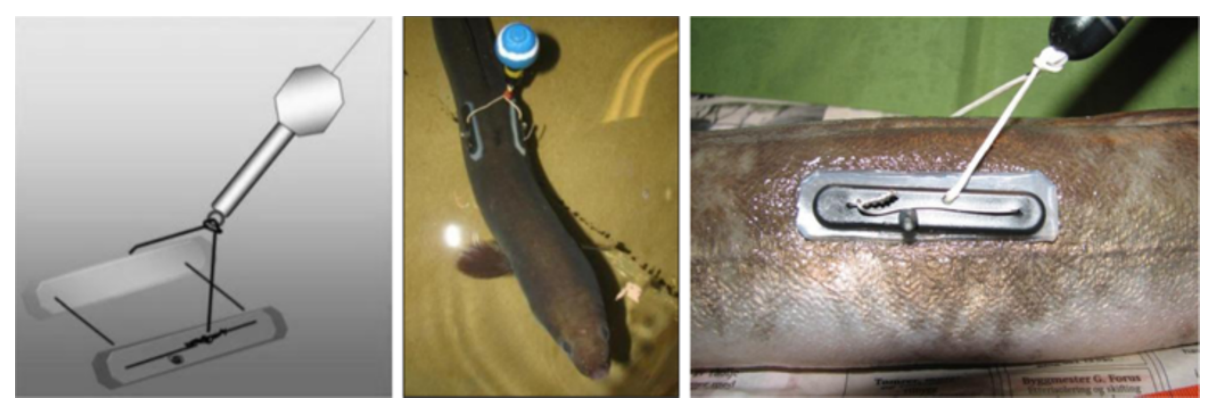

Figure 3 Illustration and pictures of the Økland tagging method used to attach pop-up satellite archival transmitters to European silver eel.

\section{Jellyman and Tsukamoto method}

This tagging method was described and used by Jellyman and Tsukamoto for attaching PSATs to longfin eel [11-13]. Three circular plastic discs were prepared, two for attachment on each side of the eel (each with one hole) and one for the back (with two holes) keeping the tag in place (Figure 4). For attachment to the eel, hollow needles were inserted from each side through the lateral musculature of the eel and upward to emerge at the dorsal line. A Teflon-coated wire was run though the first needle up to the back, then through the first hole in the plastic disc prepared for the back, through the satellite tag, before it was inserted through the second hole in the plastic disc and down through the second needle. The plastic discs prepared for the sides were threaded onto the wire on each side, the wire was pulled taut, and the position of the discs secured with wire locks. Excess wire was cut off. The holes through the plastic discs were at an angle such that the discs were aligned flat against the side of the fish when the Teflon-coated wire was tightened. The angle in the holes in the discs and the type of wire locks used differed from the methods used by Jellyman and Tsukamoto. Except for this, their published method was followed.

\section{Westerberg method}

This method was developed during this study and is based on the fact that the skin of the European eel is extremely strong and can keep the tag attached to the animal without the need to penetrate the swimming muscle. The tensile strength of eel skin is 40 to $60 \mathrm{MN} \mathrm{m}^{-2}$, which is approximately the same as mammalian tendon (HW, unpublished data). The method uses three attachment points, although at any one time the drag force is primarily exerted on only one. Therefore, should the first attachment point come loose the attachment will be held in place by the second attachment point, which in the meantime has been allowed to heal better due to lower disturbance. If the second attachment point fails, the third and last attachment point retains the tag.

A 25-mm-long wire with a loop in each end was made by twisting a $0.8-\mathrm{mm}$-diameter stainless steel wire. One

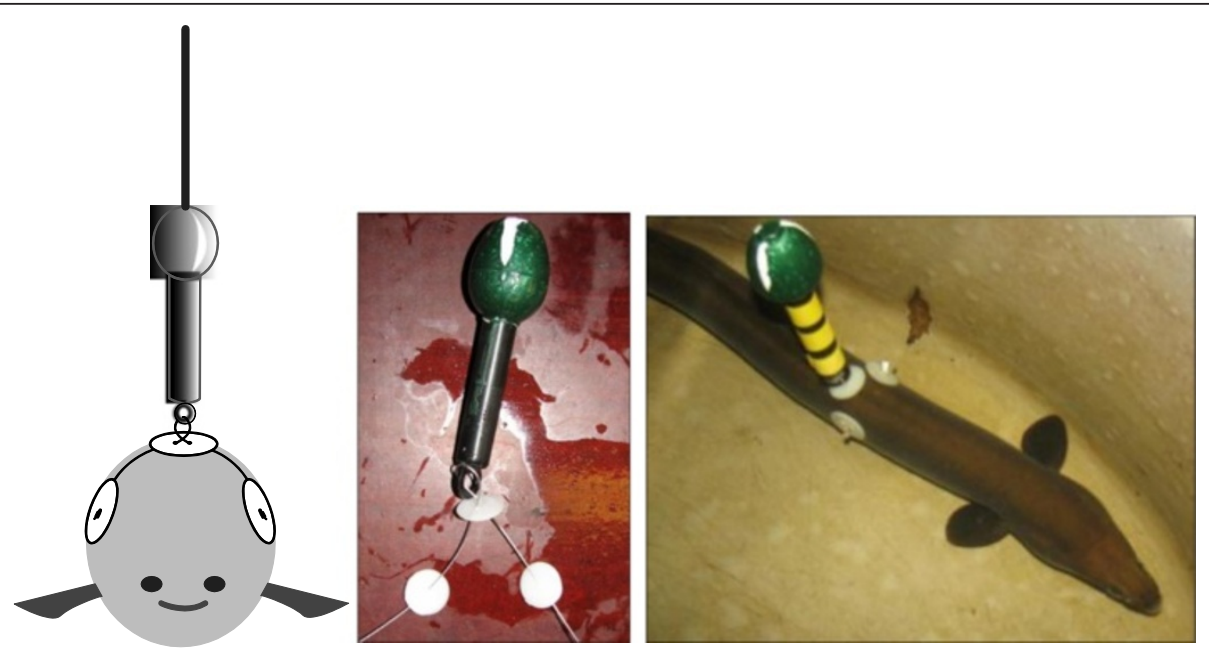

Figure 4 Illustration and photos of the Jellyman and Tsukamoto tagging method used to attach pop-up satellite archival transmitters to European silver eel. The method is slightly modified from the tagging method described by Jellyman and Tsukamoto [11-13]. 

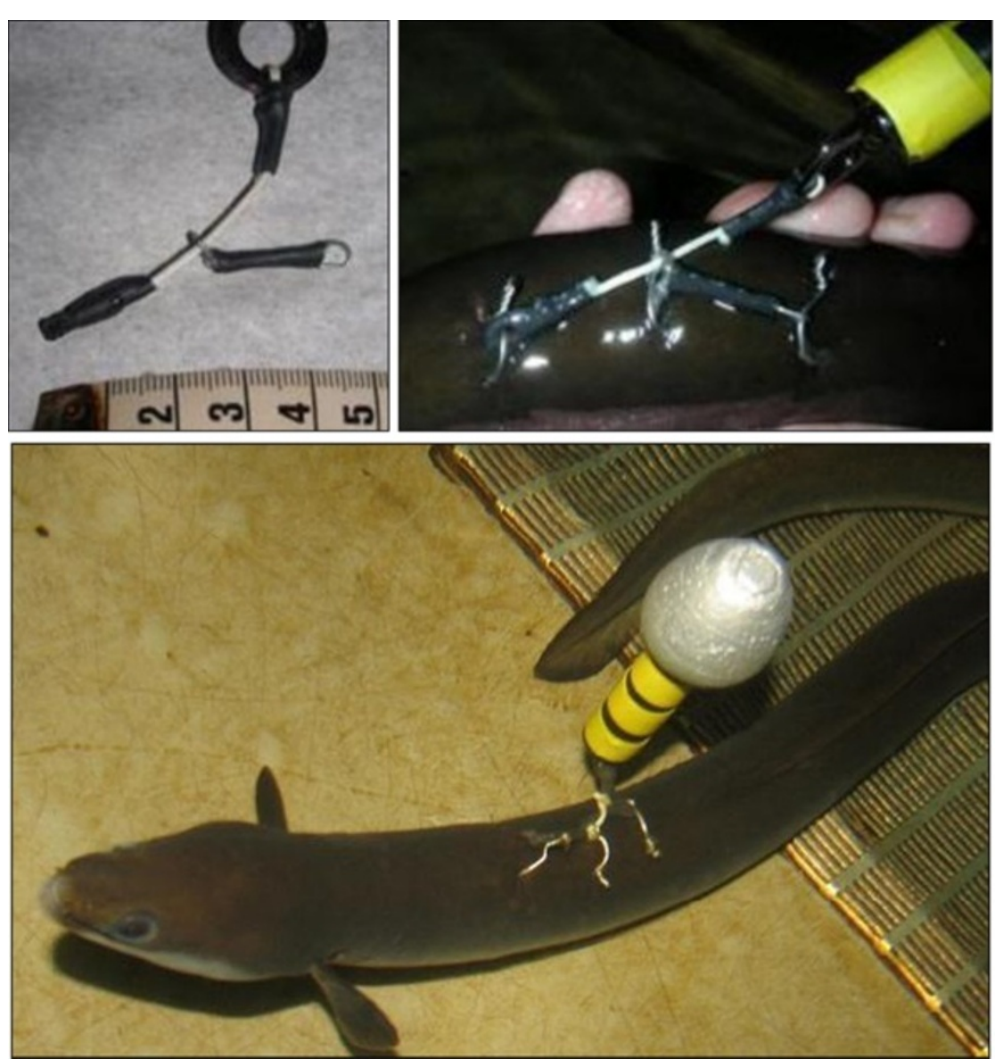

Figure 5 Photos of the Westerberg method used to attach pop-up satellite archival transmitters to European silver eel.

loop had a horizontal angle but was bent up $90^{\circ}$, and the other loop was vertical (Figure 5). The wire was covered with heat-shrink tubing. A flexible nylon leader was run from the tag through the upward facing loop. Three hollow needles were placed parallel, just under the skin on the back of the eels. Three separate 0.8 -mm-diameter stainless steel wires were threaded through the needles and placed just under the skin. The wire closest to the head of the fish was passed through the eye in the nylon leader attached to the tag and closed. The second wire was passed through the loop facing up $90^{\circ}$ and closed, and the third was passed through the vertical loop and closed.

\section{Økland-Westerberg anchor implant method}

This method was developed during this study and relies on a single attachment point using the strength of the

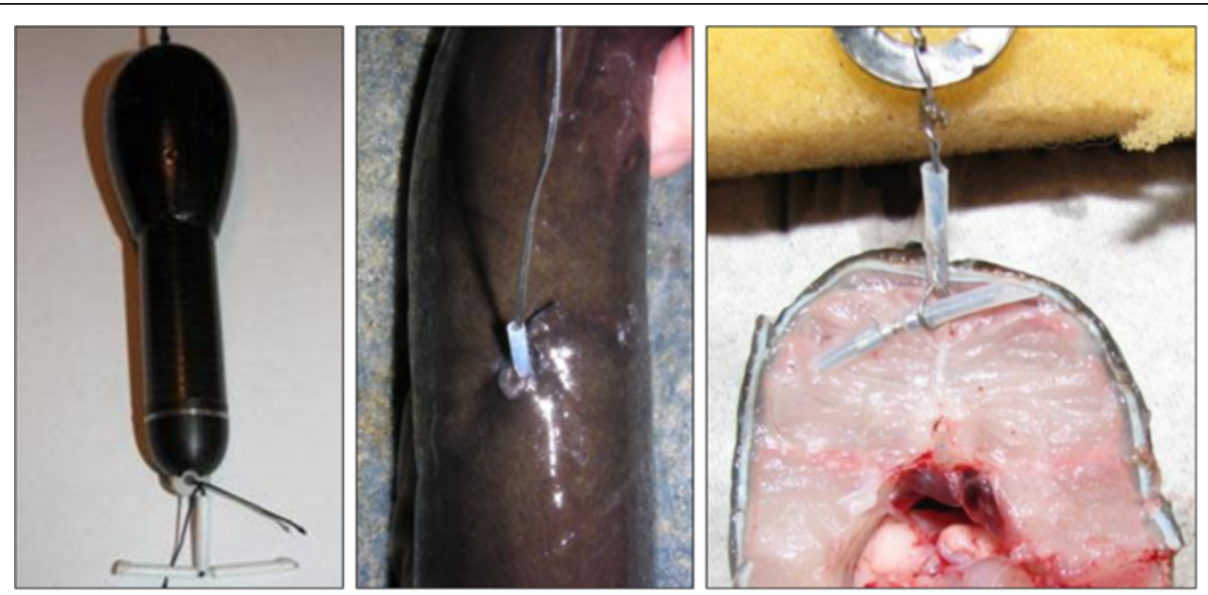

Figure 6 Photos of the Økland-Westerberg anchor implant method used to attach pop-up satellite archival transmitters to European silver eel. 
eel skin and is in principle a T-bar anchor tag (Figure 6). The anchor was made from 0.8 -mm-diameter stainless steel wire covered with heat-shrink tubes. A 25 -mm-long wire with a 3-mm loop in the end was attached to the PSAT. A small incision was made on the left side of the back of the eel using a hypodermic needle. The anchor wire was pushed below the skin towards the middle of the back of the eel, where a 4-mm incision was made. The anchor wire was guided into the loop of the wire attached to the tag and then pushed further under the skin towards the other side of the eel. The anchor wire was covered by two separate tubes, such that the loop wire from the tag rested in a small bare area between the rubber tubes. The incision on the back was closed with a single suture.

\section{Tag retention of silver eels released in field studies on European coasts}

During the EELIAD [20] and Galathea [21] projects, 97 silver eel were tagged with PSATs (X-tag, Microwave Telemetry, Inc.) using the Økland method and 63 with the Westerberg method. All were females, with a mean length of $979 \mathrm{~mm} \pm 56 \mathrm{SD}$ and a mean mass of 2,012 $\mathrm{g} \pm 306 \mathrm{SD}$. The pre-programmed release date was less than six months after tagging for 3\% of the fish, 6 to 12 months for $62 \%$ of the fish and 12 to 18 months for $35 \%$ of the fish. In addition, 115 silver eel were tagged with floating external PDSTs (model G5, Cefas Technology Ltd. Lowestoft, UK) using the Westerberg method. This tag (red colored cylinder with a diameter of $20 \mathrm{~mm}$ and length of $129 \mathrm{~mm}$ ) is comparable in size to the X-tag. The fish were released on the west coast of Ireland (98 PSAT and 20 PDST), in the Bay of Biscay (36 PSAT and 16 PDST) or on the Swedish west coast (15 PSAT and 74 PDST), with the purpose of studying ocean migration towards the spawning grounds. All releases were made in seawater and near the coast. In addition, 11 eels with PSAT were released off the shelf in $46^{\circ} 25^{\prime} \mathrm{N}$ and $17^{\circ} 00^{\prime} \mathrm{W}$. Tag retention time was identified from the tag record and analyzed.

\section{Abbreviations \\ ARGOS: Advanced Research and Global Observation Satellites; PDST: Pop-up data storage tags; PSAT: Pop-up satellite archival transmitters; SD: Standard deviation. \\ Competing interests \\ The authors declare that they have no competing interests. \\ Authors' contribution \\ $F \varnothing, H W, K A$ and JDM designed the data collection and collected the data. $F \varnothing, E B T$ and HW analyzed the data. All authors contributed to draft the manuscript and approved the final manuscript.}

\section{Acknowledgements}

The study was funded by Grant Agreement GOCE-2008212133 (EELIAD) of the European Union FP7 research program on Environment (including climate change) and prepared under project number 212133. The staff at the NINA Research Station at Ims is thanked for providing assistance during experiments. Kari Sivertsen, NINA, is thanked for drawing Figure 4. Three anonymous reviewers are thanked for providing comments that improved the manuscript. The experiments were approved by the local responsible laboratory animal science specialist under the surveillance of the Norwegian Animal Research Authority (NARA) and registered by the Authority.

\section{Author details}

${ }^{1}$ Norwegian Institute for Nature Research (NINA), Trondheim NO-7485, Norway. ${ }^{2}$ Swedish University of Agricultural Sciences, Institute of Freshwater Research, Drottningholm 178 93, Sweden. ${ }^{3}$ Technical University of Denmark, Section for Freshwater Fisheries and Ecology, Silkeborg DK-8600, Denmark.

${ }^{4}$ Centre for Environment, Fisheries and Aquaculture Science (Cefas),

Lowestoft Laboratory, Suffolk NR33 OHT, UK.

Received: 29 October 2012 Accepted: 7 February 2013

Published: 4 April 2013

\section{References}

1. Aarestrup K, Økland F, Hansen MM, Righton D, Gargan P, Castonguay M, Bernatchez L, Howey P, Sparholt H, Pedersen MI, McKinley RS: Oceanic spawning migration of the European eel (Anguilla anguilla). Science 2009, 325:1660.

2. Tesch FW: The Eel. Oxford: Blackwell Science; 2003.

3. Bridger CJ, Booth RJ: The effects of biotelemetry transmitter presence and attachment procedures on fish physiology and behaviour. Rev Fish Sci 2003, 11:13-34.

4. Thorstad EB, Økland F, Finstad B: Effects of telemetry transmitters on swimming performance of adult Atlantic salmon. J Fish Biol 2000, 57:531-535.

5. Thorstad EB, Økland F, Heggberget TG: Are long term negative effects from external tags underestimated? - Fouling of an externally attached telemetry transmitter. J Fish Biol 2001, 59:1092-1094.

6. Cottrill A, Økland F, Aarestrup K, Jepsen N, Koed A, Hunter KJ, Butterworth KG, McKinley RS: Evaluation of three telemetry transmitter attachment methods for female silver-phase American eels (Anguilla rostrata Leseur). $J$ Great Lakes Res 2006, 32:502-511.

7. Broadhurst BT, Ebner BC, Clear RC: Radio-tagging flexible-bodied fish: temporary confinement enhances radio-tag retention. Marine Freshw Res 2009, 60:356-360.

8. Burgerhout E, Manabe R, Brittijn SA, Aoyama J, Tsukamoto K, van den Thillart GE: Dramatic effect of pop-up satellite tags on eel swimming. Naturwissenschaften 2011, 98:631-634.

9. Methling C, Tudorache C, Skov PV, Steffensen JF: Pop up satellite tags impair swimming performance and energetics of the European eel (Anguilla anguilla). PLoS One 2011, 6:e20797.

10. Deelder CL: Synopsis of biological data on the eel Anguilla anguilla (Linnaeus, 1758). In FAO Fisheries Synopsis no. 80, revision 1,1984. Rome: Food and Agriculture Organization of the United Nations; 1984.

11. Jellyman D, Tsukamoto K: First use of archival transmitters to track migrating freshwater eels Anguilla dieffenbachii at sea. MEPS 2002, 233:207-215.

12. Jellyman $D$, Tsukamoto $K$ : Swimming depths of offshore migrating longfin eels Anguilla dieffenbachii. MEPS 2005, 286:261-267.

13. Jellyman D, Tsukamoto K: Vertical migrations may control maturation in migrating female Anguilla dieffenbachii. MEPS 2010, 404:241-247.

14. Winter HV, Jansen HM, Adam B, Schwevers U: Behavioural effects of surgically implanting transponders in European eel, Anguilla anguilla. In Aquatic Telemetry: Advances and Applications: Proceedings of the Fifth Conference on Fish Telemetry held in Europe. Edited by Spedicato MT, Lembo G, Marmulla G. Rome: FAO/COISPA; 2005.

15. Holliday FGT, Tytler P, Young AH: Activity levels of trout (Salmo trutta) in Airthrey Loch, Stirkling, and Loch Leven, Kinross. Proc R Soc Edinb (B) 1972, 74:315-331.

16. Hart $L G$, Summerfelt RC: Surgical procedures for implanting ultrasonic transmitters into flathead catfish (Polydictis olivaris). Trans Am Fish Soc Symp 1975, 104:56-59.

17. Beaumont WRC, Clough S, Ladle M, Welton JS: A method for the attachment of miniature radio tags to small fish. Fish Man Ecol 1996, 3:201-207.

18. Baras $E$, Jeandrain D: Evaluation of surgery procedures for tagging eel Anguilla anguilla (L.) with biotelemetry transmitters. Hydrobiologia 1998, 372:107-111.

19. Davidsen JG, Finstad B, Økland F, Thorstad EB, Mo TA, Rikardsen AH: Early marine migration of European silver eel (Anguilla anguilla) in Northern Norway. J Fish Biol 2011, 78:1390-1404. 
20. The eeliad project. http://www.eeliad.com.

21. GALATHEA 3 project. www.galathea3.dk.

22. Durif $C$, Dufour $S$, Elie P: The silvering process of Anguilla anguilla: a new classification from the yellow resident to the silver migrating stage. J Fish Biol 2005, 66:1025-1043.

23. Durif C, Guibert A, Elie P: Morphological discrimination of the silvering stages of the European eel. In Eels at The Edge: Science, Status, and Conservation Concerns. Volume 58 of American Fisheries Association. Edited by Casselman JM, Cairns DK. Bethesda, MD: American Fisheries Association; 2009:103-111.

24. Iversen $\mathrm{MH}$, Økland F, Thorstad EB, Finstad B: The efficacy of Aqui-S vet. (iso-eugenol) and metomidate as anaesthetics in European eel (Anguilla anguilla L.), and their effects on animal welfare and primary and secondary stress responses. Aquacult Res 2012, in press.

25. Wootton RJ: Ecology of Teleost Fishes. London: Chapman and Hall; 1990

doi:10.1186/2050-3385-1-3

Cite this article as: Økland et al:: Development and testing of attachment methods for pop-up satellite archival transmitters in European eel. Animal Biotelemetry 2013 1:3.

\section{Submit your next manuscript to BioMed Central and take full advantage of:}

- Convenient online submission

- Thorough peer review

- No space constraints or color figure charges

- Immediate publication on acceptance

- Inclusion in PubMed, CAS, Scopus and Google Scholar

- Research which is freely available for redistribution 